\title{
DETERMINANTS OF MERGER ACTIVITY: EVIDENCE FROM INDIA
}

\author{
Madhuri Agrawal \\ Financial Institutions Group \\ Centralised Research Group \\ J P Morgan \\ Mumbai, India \\ Email: madhuri.agrawal@gmail.com \\ and \\ Rudra Sensarma ${ }^{1}$ \\ Birmingham Business School \\ University of Birmingham \\ Birmingham B152TT, UK \\ Email: rsensarma@gmail.com
}

\begin{abstract}
This study investigates the role of industry level factors in determining merger activity in an emerging economy. The study uses information from India, which has witnessed acceleration in merger activity subsequent to recent economic reforms. Departing from the existing literature, we proxy merger activity by the occurrence of mergers and the number of mergers. The results from logistic and count data regressions suggest that growth opportunity, concentration and cash flow are important determinants of merger activity. However, unlike existing studies, no evidence is found to support the role of mergers as a corporate restructuring activity in response to industry shocks.

Key words: Mergers, Acquisitions, Occurrence, Logit Regression, Count Data Regression, Poisson Distribution, Frequency, Emerging economy, India
\end{abstract}

\footnotetext{
${ }^{1}$ Corresponding Author
} 


\section{DETERMINANTS OF MERGER ACTIVITY: EVIDENCE FROM INDIA}

\section{Introduction}

It has been widely documented that many Asian economies have witnessed dramatic increase in merger activity since the mid 1990s (see e.g. Chen and Findlay, 2003). In India, the post liberalization era (i.e. after May 1991) has been characterized by a surge in corporate restructuring activity. In the first half of 2005, merger activity in the industry formed $88 \%$ of all corporate deals in India as compared to $67 \%$ in the previous year. ${ }^{2}$ Between January and June 2004 alone, a total of 277 deals valued at \$6 billion were completed. This heightened activity and the critical role played by mergers in the growth of Indian industries makes it important to understand the features of merger activity especially because it can give us important insights into corporate restructuring in emerging economies. In this respect, we examine the role of various industry-level factors which explain incidence and frequency of mergers and acquisitions in India.

While previous studies have explored the determinants of mergers, most of these focus on developed economies (see for instance, Andrade and Stafford, 2004; Rhodes-Kropf et al, 2004; Harford, 2005). However, merger occurrence, intensity and overall importance of merger activity varies substantially across countries, depending on factors such as corporate governance mechanisms, size and structure of the capital markets, importance of banks and other sources of capital, legal structures, tradition etc. Therefore significant differences can be expected to exist between countries in terms of merger motives, merger activity and also in its economic consequences. Due to these reasons, there is a need to supplement the current literature on mergers in developed countries with evidence from emerging economies. It is therefore interesting to understand what motivates merger activity in an emerging economy like India which has only lately begun adopting such corporate practices following recent changes in its legal and economic frameworks.

\footnotetext{
${ }^{2}$ Source: INDATA survey conducted by India Advisory Partners, available at http://www.thehindubusinessline.com/2005/08/12/stories/2005081200541100.htm
} 
Most studies on determinants of mergers have used investment in mergers (which is a continuous variable) to proxy merger activity which is then taken as the dependent variable in a regression framework (e.g. Andrade and Stafford, 2004). However it may be argued that the question of why firms choose to invest in acquisitions can be better answered by looking at the actual decision in terms of occurrence and frequency of mergers rather than the value. For this reason it is important to investigate the determinants of merger occurrence and the frequency of these occurrences. In this paper we differ from the existing literature by examining the motives behind the decision of firms to go for acquisitions which we proxy by the occurrence of a merger (which is a qualitative variable) and by the number of mergers that occur in an industry (which is a discrete variable). This requires us to employ logistic and count data regression models instead of standard regression methodology which has been mostly used in the literature.

Thus, our work attempts to contribute to the existing literature in several ways. First, we provide evidence from mergers in a developing country. Second, we examine the role of industry level variables on the occurrence of mergers using logistic regression models. Third, we demonstrate an interesting application of count data regression models to investigate the determinants of frequency of mergers. Fourth, we provide evidence that suggests that while mergers in India are driven by growth and consolidation motives, but in contrast with existing evidence for developed countries, Indian firms are reluctant to restructure when the industry faces shocks. The remainder of the paper is structured as follows. Section 2 reviews some existing evidence on determinants of mergers. Section 3 describes our data-set and the empirical strategy. Section 4 presents and discusses the results, which is followed by concluding remarks in Section 5.

\section{Received Evidence}

Several studies have attempted to explain the motives behind merger activity, by examining factors at the firm level as well as at the industry level. Attainment of synergic benefits has frequently been found to be a significant merger motive. For instance, Maquieira, Megginson, and Nail (1998) examine 260 mergers in the US between 1963 
and 1996 and record significant net synergistic gains in non-conglomerate mergers and insignificant net gains in conglomerate mergers. Bradley, Desai, and Kim (1988) find that a successful merger offer increases the combined value of the merged entity by an average of $7.4 \%$. Another documented firm-level reason for mergers is efficiency. Rhoades (1998) investigates this motive through nine case studies of bank mergers in the US and finds significant cost cutting in all cases. Four out of these nine mergers show clear efficiency gains relative to peers. Bruner (1988) examines excess cash and debt capacity as a motive for mergers and finds evidence to support the theory of Myers and Majluf (1984) that suggests that "slack-rich" bidders pair with "slack-poor" targets to create value.

Apart from firm level explorations, there is evidence of merger waves occurring within industries suggesting that there are certain factors operating on an industry level that determine merger activity (Brealy and Myers, 2003). Mitchell and Mulherin (1996) report significant clustering of merger activity by industry and correlate these clusters with economic, regulatory and technology shocks in the industry. Studies by Mulherin and Boone (2000) and Andrade et al (2001) also confirm the presence of such waves. However, there are dichotomies in understanding the causes of such waves. Harford (2005) classifies these causes as neoclassical and behavioural. Under the neoclassical studies, an interesting work is that by Jovanovic and Rousseau (2002) who argue that technological changes lead to dispersion in Tobin's q and results in 'high q' firms taking over 'low q' firms in the industry. Another study is by Harford (1999) who shows that higher cash resources are associated with higher takeover activity. Amongst the studies attributing behavioural causes to merger waves is the work of Rhodes-Kropf et al (2004). This paper suggests that merger waves occur when the aggregate industry market valuation, measured as market to book value ratio, is higher compared to various estimates of true valuations. The authors note that these valuations could be both due to misplacements and actual presence of growth opportunities.

In a recent paper, Andrade and Stafford (2004) determine motivating factors for mergers both at industry and firm levels. The authors investigate the economic role of mergers in 
the US by performing a comparative study of mergers and other forms of corporate investment at both industry and firm levels. They find that industry capacity utilization has opposite effects on merger and non-merger investments particularly during the 1970s and 1980s. While excess capacity drove industry consolidation through mergers, peak capacity utilization induced industry expansion through non-merger investment. This suggests that one mechanism through which mergers enable industry restructuring is by inducing exit in times of industry wide excess capacity. This phenomenon is reversed in the 1990s when merger intensity is found to be the highest in industries with strong growth prospects, high profitability and near full capacity. Moreover at the firm-level the paper finds that both merger and non-merger investments are positively related to the Tobin's q value of the acquirer. These results point towards an expansionary motive behind mergers.

While most of the above papers have focused on explaining the value of merger deals or merger intensity, Hijzen et al (2005) is the only study that we know of that deals with the number of mergers. The paper investigated the role of trade-costs in explaining the number of cross border mergers in OECD countries. Our paper, on the other hand, studies the determinants of merger occurrence as well as the number of mergers in the industrial sector of an emerging economy, viz. India. Focusing on merger occurrence and frequency enables us to answer the questions of which industries are likely to experience mergers and what determines the number of merger deals.

Empirical evidence on merger motives in India is scarce. Basant (2000) suggests that economic reform in the Indian economy has significantly reduced micro-economic rigidities and enhanced competitive pressures. In response, firms have undertaken corporate restructuring activity in order to retain competitiveness and increase their value. Beena (2000), in a study of Indian industries, records an overwhelming dominance of mergers between related firms (i.e. those belonging to the same group or management) even while there are signs of an increase in mergers between unrelated firms. In another study, Beena (2004) finds evidence of mergers within the same group with the motive of consolidation of control to protect against takeovers but does not find any role of 
efficiency-related parameters in determining merger activity in India. The author instead suggests a merger motive of growth in size by acquiring higher equity.

The aforesaid discussion indicates that most studies examining merger motives have focused on merger intensity in developed countries and those on India have not formally tested for the importance of different motives. Our paper attempts to empirically examine the importance of different industry-level factors to explain merger activity. For this purpose we investigate the determinants of merger occurrence as well as merger frequency. In brief, our results point towards the importance of growth opportunity, concentration and excess cash in explaining merger activity in India.

\section{Data and Methodology}

\section{Sample}

The main problem in conducting a study of mergers and acquisitions in India, as in most emerging economies, is the absence of a readily available database on mergers. For our purpose, we constructed a data-set of mergers in Indian industries during the period 2002 to 2004 by compiling information from different sources. The Securities and Exchange Board of India (SEBI), which is the stock market regulator, makes it mandatory for listed firms to make public announcements of their mergers or acquisitions to the stock market. The publicly available Prowess database, maintained by the CMIE (Centre for Monitoring Indian Economy), records all such announcements. Therefore, in order to create our sample of mergers, we went by the list of all merger announcements during 2002 to 2004 recorded in the Prowess database, and cross-checked each announcement of a merger or acquisition with media reports available on the internet. By following this process, we were able to arrive at a data-set comprising of 109 mergers during the period of 2002 to 2004. We used CMIE Industry classifications for aggregating the data into industry level information. Finally for each industry and merger case, we extracted the required financial information again from the Prowess database. Since there was more than one merger in some industries, we ended up with a sample of 83 industry level observations. 


\section{Empirical Model and Variables}

In their study of industry-level determinants of mergers, Andrade and Stafford (2004) examined the degree to which merger intensity is related to factors such as industry growth prospects, shocks to industry structure and industry concentration. In our paper however, the focus is on the determinants of occurrence and frequency of mergers instead of the investment value. Hence in our regression framework, the industry level merger activity is studied in terms of two dependent variables:

i. A categorical variable to denote whether or not mergers occur in an industry in a particular year (takes value 1 if a merger occurs and 0 otherwise).

ii. A count variable to denote the number of mergers in an industry in a given year. As potential determinants of these variables, we computed several industry-level explanatory variables by using data from the Prowess database. These are presented in Table 1.

\section{(Table 1 here)}

We employ Tobin's q as an explanatory variable to investigate the role of mergers as investments, in line with the q-theory which suggests that all forms of investments should be positively linked with q. Though the q-theory is firm specific, we have extended it to the industry level analysis as growth prospect is typically common to an industry. Our measure of Tobin's q assumes that market value of debt is correctly captured by its book value, an assumption that is frequently used in empirical studies. In addition to the continuous Tobin's q variable, we also use a set of dummy variables to differentiate between high q, low q and medium q firms. The reason for using these dummy variables is that an alternative interpretation of the q-theory suggests a demarcation between industries that should go for merger investments based on growth prospects, and those that should not (Andrade and Stafford, 2004). Therefore, in each year we sort the industries on the basis of q, classifying the bottom third as 'low q' and the top third as 'high q', and then assign them dummy variables of the same name.

Cash flow and sales growth also act as proxies for growth opportunity in the industry while industry concentration, as measured by the Hirshman-Herfindahl Index, acts as a 
proxy for the industry structure. We measure shocks to the industry by the differential of current sales growth and the median sales growth of the industry for the period under study. Using different combinations of these variables, we specify four different models to examine the importance of the above factors in determining mergers. These models are summarized in Table $2 .^{3}$

(Table 2 here)

\section{Econometric Methodology}

As mentioned earlier, we consider two different dependent variables as our measures of merger activity. For each dependent variable, we estimate all the above four models using the appropriate econometric technique. These are explained as follows.

Merger Occurrence: In this set of regressions, the dependent variable is the occurrence of merger in an industry captured by a dummy variable. Since this is a case of a binary dependent variable, we employ the logistic regression technique that models the probability of occurrence of mergers in an industry as follows:

$\ln \left[p_{i} /\left(1-p_{i}\right)\right] \equiv a+b X_{i}+u_{i}$

where $p_{i}$ refers to the probability of a merger occurring in the $i^{\text {th }}$ industry and $X_{i}$ represents the determinants of merger activity.

Number of Mergers: In this case, the objective is to model the frequency of occurrence of mergers in an industry. Therefore, the dependent variable is the number of mergers that occur in an industry. Since this is an integer and not a continuous variable, ordinary least squares regression will lead to biased, inefficient and inconsistent estimates (Cameron

\footnotetext{
${ }^{3}$ While these alternative specifications allow us to compare our results with previous studies (e.g. Andrade and Stafford, 2004), we also tried a variable for industry size (number of firms or total assets) in our estimations. Industry size can control for the possibility that a big industry may witness more mergers than others simply because it has more firms. All our results remain qualitatively unchanged with the size control, albeit with weaker significance owing to multi-collinearity, and are available on request. We choose to report the estimations without including size to enable comparison with Andrade and Stafford (2004). Moreover, size is highly correlated with Concentration as an industry with a large number of firms is likely to be less concentrated, thus causing multi-collinearity problems. Therefore, in our reported results where we do not include size, Concentration is expected to take care of any possible size factor as well.
} 
and Trivedi, 1998). Therefore we apply the econometric technique of count data regression to estimate the following model:

$$
\left.E\left[Y \mid X_{i}\right)\right] \equiv a+b X_{i}+u_{i}
$$

where $E[Y \mid X]$ is the conditional mean of the number of mergers and is assumed to be $\log$ linearly related to the explanatory variables. The choice of the distributional assumption for the dependent variable is made by a chi-square test of over-dispersion (Cameron and Trivedi, 1998) which leads us to use the Poisson distribution in our estimations.

\section{Results and Discussion}

Before estimating the relationship between merger activity and its industry level determinants, we present a descriptive overview of our data-set. Table 3 provides a summary of the merger activity across industries in our sample. Intensity of merger activity is measured by the book value of the merged entity expressed as a percentage of the total assets of the industry. We find that out of the 109 mergers occurring in Indian industries, bulk of the mergers have occurred in the chemicals industry and the financial services industry. However merger intensity has been highest in the petroleum industry followed by the computer hardware industry, which is not surprising given the presence of high value firms in these industries.

(Table 3 here)

(Figure 1 here)

Figure 1 plots the year-wise distribution of merger intensity and number of mergers for all industries. The graph indicates that the overall merger intensity has been highest in 2002 and has decreased since then, while the number of mergers has been the lowest in 2003 and almost the same in 2002 and 2004. Moving on to the explanatory variables, Table 4 presents the correlation coefficients of the number of mergers each industry with the industry level factors. This table gives an indication of the nature of the relation between merger activity and the explanatory variables. It appears that Cash and Tobin's q are both positively related to the number of mergers. At a preliminary level, this result gives early indication of the role of mergers as investments and the positive link between 
mergers and growth opportunity. The negative correlation between mergers and concentration suggests that mergers occur with the view of consolidation in an industry and are therefore dependent on the value of the concentration index in the industry. Less concentrated businesses try to attain market power by merging entities. The negative relation of mergers with both shock and sales growth is surprising and suggests that firms in Indian industries do not use mergers as a means of restructuring but rather avoid such restructuring activity when shocks occur.

(Table 4 here)

We now move to the estimated relationships between merger activity and industry level explanatory variables. The estimates from the logistic regressions that model the occurrence of mergers are presented in Table 5. The coefficient of Cash indicates that merger activity in an industry is positively associated with cash flow but the effect is not statistically significant except for in model 4 where it is significant at the 10 percent level. This is in concurrence with previous studies (e.g. Andrade and Stafford, 2004) which suggest that higher cash flows lead to higher investment activity. The coefficient of Concentration in each model is negative and significant at conventional levels indicating that businesses undergo mergers to consolidate and hence incidence of mergers is high in a low concentration industry.

(Table 5 here)

The coefficient of Tobin's q is positive and significant in each of the models (although it is only weakly significant at 11 percent in model 4). This is in accordance with the $q$ theory of investment. In other words, there is a higher likelihood of mergers occurring in an industry that has higher growth prospects, even though q may be unable to capture all the growth effects. On the other hand, the high q and low q dummy variables do not significantly impact merger incidence. The positive relation between merger occurrence and growth appears to get reinforced by the positive coefficients of Sales growth, which might capture some of the components of growth opportunity that is not covered by our definition of q. However the coefficients are not statistically significant at conventional levels. An interesting difference with the results of Andrade and Stafford (2004) is the 
negative association that we find between Shock and occurrence of mergers. This appears to confirm our preliminary findings from the correlation analysis that firms in Indian industries shrinks away from investment activity in the form of mergers when facing a shock and wait for the shock to subside before going for a merger. This result might also imply that mergers are not undertaken as a restructuring activity to remove inefficiencies.

Finally we examine the impact of industry level factors on merger activity in terms of the number of mergers in each industry. The results from count data regressions are presented in Table 6. The relations found earlier in the logistic regressions appear to get reinforced in the count data regressions. Cash has a positive and statistically significant impact on the number of mergers. Thus, the more cash flows in an industry, the higher is the number of mergers undertaken for investment of the excess cash. Concentration again emerges as a significant determinant of mergers with its negative coefficients indicating that higher number of mergers occurs in industries which are more fragmented. These industries rapidly move towards concentration of sellers in the market by merging different entities. Therefore our results seem to suggest that industry structure plays an important role in determining merger activity.

(Table 6 here)

The coefficient of Tobin's q in each of the estimated models is positive but statistically significant only in model 4. Both Cash flow and Tobin's q being proxies for growth opportunity, our results strengthen the view that more mergers are undertaken if avenues of growth are more, hence supporting the expansionary role of mergers. Interestingly, Tobin's q turns out to be a significant determinant of merger frequency only when high q and low q firms are separately controlled for by using dummy variables. This suggests that continuity of the relationship between mergers and growth becomes prominent within groups of low-q, high-q and medium-q firms. Moreover, the emergence of the high-q dummy as a variable with positive and significant coefficient reinforces our previous findings on the expansionary role of mergers. 


\section{Conclusions and Implications}

The present study tries to contribute to the empirical literature on mergers by investigating merger motives in an emerging economy. An additional contribution of this paper is the modelling of occurrence and frequency of merger deals which can better capture the decision to go or not go for mergers, instead of modelling the value. By conducting logistic and count data regressions respectively for occurrence and number of mergers in an industry, we have examined the role of industry level variables in merger activity. The results highlight low concentration, high cash flows and high Tobin's q as factors that explain the occurrence and frequency of mergers in Indian industries.

One implication of our results is that they suggest the roles played by mergers in India. These roles involve consolidating resources in fragmented industries and supporting the growth of industries that have the potential to grow. Thus our findings indicate the presence of firms in Indian industries who undertake merger activity to leverage the growth potential available to them. These results are in broad conformation with available evidence from developed economies. On the other hand, in contrast with Andrade and Stafford (2004), we find no evidence to support the role of mergers as a restructuring activity since in our case merger activity turns out to be negatively linked to industry shocks. This result appears to suggest that Indian firms are reluctant to go for mergers during periods of industry wide shocks. This may be an outcome of the fact that product market competition and corporate strategies are immature or nascent in recently deregulated economies. This makes the firms cautious and risk averse, as compared with the experiences in most of the developed world. 


\section{References}

Alexander Hijzen, Holger Görg and Miriam Manchin, 2005 “Cross-Border Mergers \& Acquisitions and the Role of Trade Costs", Research Paper Series, University of Nottingham, Research Paper 2005/17

Andrade Gregor, Stafford Erik, 2004 "Investigating the economic role of mergers", Journal of Corporate Finance Vol.10 (2004) pp1 - 36

Andrade, G., Mitchell, M., Stafford, E., 2001. "New evidence and perspectives on mergers” Journal of Economic Perspectives" Vol.15, pp103-120.

Basant R., 2000, “Corporate Response to Economic Reforms", Economic and Political Weekly March 4, 2000

Beena P.L., 2000, “An Analysis of Mergers in the Private Corporate Sector in India”, Working Paper 355, Centre for Development Studies, Trivandrum.

Beena P.L., 2004, "Towards Understanding the Merger Wave in the Indian Corporate Sector: A comparative Perspective”, Working Paper 301, Centre for Development Studies, Trivandrum.

Bradley, Michael, Anand Desai, and E. Han Kim, 1988, "Synergistic Gains from Corporate Acquisitions and Their Division between the Stockholders and Target and Acquiring Firms," Journal of Financial Economics 21 (No. 1, May), 3-40.

Brealey, R. and Myers, S., 1996 Principles of Corporate Finance, 5th edition. McGrawHill, New York.

Bruner, Robert F., 1988, “The Use of Excess Cash and Debt Capacity as a Motive for Merger", Journal of Financial \& Quantitative Analysis, Vol. 23 Issue 2, p199, 19p

Cameron, A. C., and Trivedi, P. K., 1998, Regression Analysis of Count Data, Cambridge University Press, Cambridge, UK

Chen, C. and Findlay, C., 2003, "A Review of Cross-border Mergers and Acquisitions in APEC”, Asian-Pacific Economic Literature, Vol. 17(2), p 14-38.

Harford J., 1999, “Corporate Cash Reserves and Acquisitions”, Journal of Finance, Vol. 54, pp 69-97

Harford J., 2005, “What drives Merger waves”, Journal of Financial Economics, Vol. 77 (3), pp 529-560 
Jovanovic B. and Rousseau P.L. 2002, "The Q-theory of Mergers", Working Paper NYU Maquieira, Carlos P., William L. Megginson, and Lance Nail, 1998, "Wealth Creation versus Wealth Redistribution in Pure Stock-for-Stock Mergers," Journal of Financial Economics 48 (No. 1, April), 3-33.

Mitchell, M., Mulherin, J., 1996. "The impact of industry shocks on takeover and restructuring activity", Journal of Financial Economics Vol. 41, pp193-229.

Mulherin, J., Boone A., 2000 "Comparing acquisitions and divestitures", Journal of Corporate Finance Vol. 6, pp117-139.

Myers, S.C., and N.S. Majluf, 1984 "Corporate Financing and Investment Decisions when Firms Have Information that Investors do not have." Journal of Financial Economics, 13 (June 1984), pp187-221

Rhoades, Stephen A, 1998, "The Efficiency Effects of Bank Mergers: An Overview of Case Studies of Nine Mergers," Journal of Banking and Finance 22 (No. 3, March), 273-291.

Rhodes-Kropf M., Robinson D. and Vishwanathan S., 2004, Valuation Waves and Merger Activity: the empirical evidence, Working Paper: Duke University Trautwein, Friedrich, 1990, "Merger Motives and Merger Prescriptions," Strategic Management Journal 11 (No. 4, May/June), 283-295. 


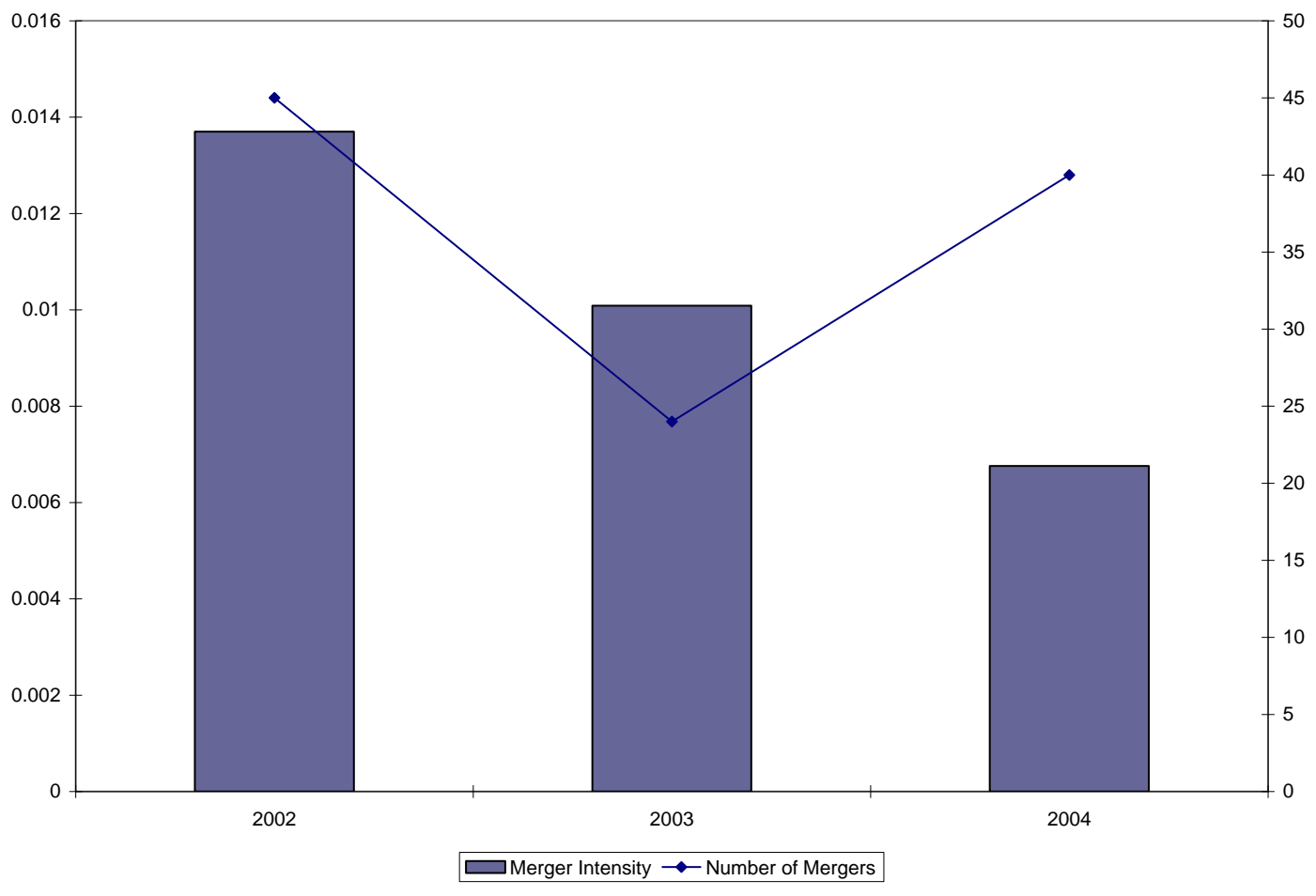

Figure 1: Merger Activity by Year

Table 1: Variables used in the Model

Variables

Tobin's q

Cash Flow (Cash)

Sales growth

Shock

Industry Concentration (Concentration)

Note: Each of the variables has been taken for the acquiring industry and not the acquirer industry. 


\begin{tabular}{lc}
\hline \multicolumn{2}{c}{ Table 2: Independent Variables in each of the Model under Investigation } \\
\hline \multicolumn{1}{c}{ Model } & \multicolumn{1}{c}{ Independent Variables } \\
\hline Model 1 & Tobin's q, Cash, Concentration, Shock \\
Model 2 & Same as 1, but replaces Shock with Sales growth \\
Model 3 & Same as 1, but additionally uses Sales growth \\
Model 4 & Same as 3, but additionally uses high-q and low-q \\
\hline
\end{tabular}

\begin{tabular}{|c|c|c|}
\hline \multicolumn{3}{|c|}{ Table 3: Industry-wise Mergers in India (2002-2004) } \\
\hline$\overline{\text { INDUSTRY }}$ & $\begin{array}{c}\text { Average Intensity of } \\
\text { Merger Activity }\end{array}$ & $\begin{array}{c}\text { Total number of } \\
\text { Mergers }\end{array}$ \\
\hline Automobile & 0.024 & 5 \\
\hline Chemicals & 0.394 & 16 \\
\hline Communication Services & 0.233 & 3 \\
\hline Communications & 0.000 & 0 \\
\hline Computer Hardware & 6.863 & 2 \\
\hline Construction & 0.003 & 2 \\
\hline Consumer Electronics & 0.000 & 1 \\
\hline Diversified & 0.300 & 1 \\
\hline Electrical Machine & 0.010 & 1 \\
\hline Electricity & 0.000 & 0 \\
\hline Financial Services & 2.555 & 16 \\
\hline Food \& Beverages & 0.183 & 11 \\
\hline General Purpose Machinery & 0.000 & 0 \\
\hline Health Services & 0.000 & 0 \\
\hline Industrial Machine & 0.134 & 1 \\
\hline Information Technology & 0.135 & 4 \\
\hline Metals & 1.909 & 7 \\
\hline Mining & 0.161 & 1 \\
\hline Miscellaneous Manufacturing & 0.062 & 1 \\
\hline Miscellaneous Services & 0.000 & 0 \\
\hline Non-Metallic Minerals & 0.657 & 3 \\
\hline Other Electronics & 0.036 & 1 \\
\hline Petroleum & 8.434 & 5 \\
\hline Pharmaceuticals & 0.887 & 13 \\
\hline Recreational & 0.048 & 5 \\
\hline Textiles & 0.037 & 5 \\
\hline Trading & 0.080 & 4 \\
\hline Transport Services & 3.500 & 1 \\
\hline
\end{tabular}




\section{Table 4: Correlation of number of mergers in each industry with industry level}

variables

\begin{tabular}{cc}
\hline Variable & Number of Mergers \\
\hline Cash & 0.21141 \\
Concentration & -0.32236 \\
Sales growth & -0.10939 \\
Shock & -0.09688 \\
Tobin's q & 0.098279 \\
\hline
\end{tabular}

Table 5: Results of Logistic Regression of Occurrences of Mergers on Industry Level Variables

\begin{tabular}{|c|c|c|c|c|}
\hline & Model 1 & Model 2 & Model 3 & Model 4 \\
\hline Constant & $\begin{array}{c}-0.3406 \\
(0.6275)\end{array}$ & $\begin{array}{c}-0.3132 \\
(0.6484)\end{array}$ & $\begin{array}{c}-0.2219 \\
(0.7402)\end{array}$ & $\begin{array}{c}0.0564 \\
(0.942)\end{array}$ \\
\hline Cash & $\begin{array}{c}1.7144 \\
(0.2928)\end{array}$ & $\begin{array}{c}1.2129 \\
(0.4286)\end{array}$ & $\begin{array}{c}2.3117 \\
(0.1641)\end{array}$ & $\begin{array}{c}3.04323 \\
(0.0813)\end{array}$ \\
\hline Concentration & $\begin{array}{c}-7.0087 \\
(0.0593)\end{array}$ & $\begin{array}{c}-8.5115 \\
(0.0269) \\
\end{array}$ & $\begin{array}{c}-8.2820 \\
(0.0323) \\
\end{array}$ & $\begin{array}{c}-8.4517 \\
(0.0206) \\
\end{array}$ \\
\hline Tobin's q & $\begin{array}{c}0.7779 \\
(0.0272)\end{array}$ & $\begin{array}{c}0.7603 \\
(0.0285)\end{array}$ & $\begin{array}{c}0.6396 \\
(0.0442)\end{array}$ & $\begin{array}{c}0.6664 \\
(0.1115)\end{array}$ \\
\hline Sales growth & & $\begin{array}{c}0.4155 \\
(0.7227) \\
\end{array}$ & $\begin{array}{c}3.3051 \\
(0.1572) \\
\end{array}$ & $\begin{array}{c}3.0530 \\
(0.1757) \\
\end{array}$ \\
\hline Shock & $\begin{array}{c}-0.7754 \\
(0.4389)\end{array}$ & & $\begin{array}{c}-2.1679 \\
(0.1176)\end{array}$ & $\begin{array}{c}-2.1199 \\
(0.1087)\end{array}$ \\
\hline High q & & & & $\begin{array}{c}-0.5294 \\
(0.4735)\end{array}$ \\
\hline Low $\mathrm{q}$ & & & & $\begin{array}{c}-0.7393 \\
(0.2642) \\
\end{array}$ \\
\hline AIC & 1.3266 & 1.3335 & 1.3277 & 1.3570 \\
\hline $\mathrm{SC}$ & 1.4723 & 1.4792 & 1.5026 & 1.5902 \\
\hline No. of Observations & 83 & 83 & 83 & 83 \\
\hline
\end{tabular}

Note: The values reported in parentheses are the p-values based on Huber-White standard errors that are robust to misspecifications of the underlying distribution of the dependent variable. 
Table 6: Results of Count Data Regression of Number of Mergers on Industry Level Variables

\begin{tabular}{|c|c|c|c|c|}
\hline & Model 1 & Model 2 & Model 3 & Model 4 \\
\hline Constant & $\begin{array}{c}0.4712 \\
(0.1569)\end{array}$ & $\begin{array}{c}0.4708 \\
(0.1546)\end{array}$ & $\begin{array}{c}0.4699 \\
(0.1602)\end{array}$ & $\begin{array}{c}0.3776 \\
(0.1733)\end{array}$ \\
\hline Cash & $\begin{array}{c}1.6769 \\
(0.0192)\end{array}$ & $\begin{array}{c}1.6738 \\
(0.0141)\end{array}$ & $\begin{array}{c}1.6973 \\
(0.0205)\end{array}$ & $\begin{array}{c}2.676 \\
(0.0048)\end{array}$ \\
\hline Concentration & $\begin{array}{c}-7.7345 \\
(0.0205)\end{array}$ & $\begin{array}{c}-7.8613 \\
(0.0102)\end{array}$ & $\begin{array}{c}-7.7856 \\
(0.0151)\end{array}$ & $\begin{array}{c}-7.4196 \\
(0.0095)\end{array}$ \\
\hline Tobin's q & $\begin{array}{c}0.0434 \\
(0.4596)\end{array}$ & $\begin{array}{c}0.0389 \\
(0.5399)\end{array}$ & $\begin{array}{c}0.0393 \\
(0.5354)\end{array}$ & $\begin{array}{c}-0.1702 \\
(0.0288)\end{array}$ \\
\hline Sales growth & & $\begin{array}{c}0.1328 \\
(0.8916)\end{array}$ & $\begin{array}{c}0.2401 \\
(0.848)\end{array}$ & $\begin{array}{c}0.1489 \\
(0.8948)\end{array}$ \\
\hline Shock & $\begin{array}{c}-0.0105 \\
(0.9838)\end{array}$ & & $\begin{array}{c}-0.0984 \\
(0.8751)\end{array}$ & $\begin{array}{c}0.0932 \\
(0.8745)\end{array}$ \\
\hline High q & & & & $\begin{array}{c}0.7335 \\
(0.0210)\end{array}$ \\
\hline Low q & & & & $\begin{array}{r}-0.493796 \\
(0.2501) \\
\end{array}$ \\
\hline$\overline{\mathrm{AIC}}$ & 3.3600 & 3.3596 & 3.3834 & 3.2422 \\
\hline $\mathrm{SC}$ & 3.5057 & 3.5053 & 3.5582 & 3.4753 \\
\hline No.of Observations & 83 & 83 & 83 & 83 \\
\hline
\end{tabular}

Note: The values reported in parentheses are the p-values based on Huber-White standard errors that are robust to misspecifications of the underlying distribution of the dependent variable. 